\title{
Mobile Learning Application Based On Hybrid Mobile Application Technology Running On Android Smartphone and Blackberry
}

\author{
Djoni Haryadi Setiabudi, Lady Joanne Tjahyana,Winsen \\ Informatics Department \\ Petra Christian University \\ Surabaya, Indonesia \\ djonihs@petra.ac.id,joanne@petra.ac.id
}

\begin{abstract}
Nowadays some universities have been using elearning in the teaching-learning process.Generally e-learning available in the form of web based application, but does not exist in the form of mobile application yet. Problem that arise when using a mobile device is the screen size is too small, so that the user need to zoom and scroll to get comfortable viewing. Another problem is the user using varying operating system such as android, blackberry and iOS. To overcome those problems, this research is conducted to assist in the teaching-learning process by developing a model of mobile e-learning application that can run on cross-platform, which is on Android and BlackBerry platform.

The application is created using PhoneGap that uses HTML5, CSS3, and JavaScript based on Hybrid Mobile Application. The system on the application follows Lentera e-learning system based on Moodle. Lentera is a web based e-learning system used in Petra Charistian University. On the server side, it takes a modified Moodle's source code based on PHP so the application can be run in accordance with the system. The application has a different interface from the website version. The interface is designed to be suitable on smartphone which is has limited screen space.

The result shows that the application can run on crossplatform, those are Blackberry and Android smartphone. The application also runs online together with the Lentera website. The basic features of Lentera have been successfully implemented on this application. Assessment of the application as a whole is more than $50 \%$ of respondents answered very good.
\end{abstract}

Keywords-mobile learning; Hybrid Mobile Application; smart phone; android; blackberry; cross platform; phonegap

\section{INTRODUCTION}

Nowadays, many universities have taken advantage of elearning in the form of a website in the lecturing. Both students and faculties who want to access the e-learning should find for a computer or laptop. However the physical size of a computer, laptop, or something like that is such a large and not convenience to carry out.

Considering the condition today, mobile devices have become a way of life for many people. Computers are now replaced by smartphones that can be inserted into a pocket and can be taken anywhere. However, the problem that arise is on a device with a small screen, users need to zoom and scroll to get the comfortable viewing.
According the rapid development of technology, the operating systems for mobile devices are also getting popular such as iOS, Android, Blackberry, WebOS, Symbian, and others. Various operating systems raise the new problem in developing the mobile e-learning (called mobile learning), because of differences in the programming language and the differences in how the operation of each mobile device.

Currently, there is hybrid application technology that can overcome the problem of many different operating systems on mobile phone. This new technology can be used in developing the e-learning mobile phone application. Furthermore, the mobile phone application can be uploaded to the application store, so it can be downloaded by another users. In this research, will be developed a mobile learning application which is a further development of the existing web based applications.

\section{MOBILE LEARNING}

The term mobile learning (m-learning) refers to the use of mobile and handheld IT devices, such as Personal Digital Assistants (PDAs), mobile telephones, smartphones and tablet PC technologies, in teaching and learning. [5]

As computers and the internet become essential educational tools, the technologies become more portable, affordable, effective and easy to use. This provides many opportunities for widening participation and access to ICT, and in particular the internet. Mobile devices such as phones and PDAs are much more reasonably priced than desktop computers, and therefore represent a less expensive method of accessing the internet. The introduction of tablet PCs now allows mobile internet access with equal, if not more, functionality than desktop computers.

Mobile learning now currently be most useful as a supplement to ICT, web learning and more traditional learning methods, and can do much to enrich the learning experience. In the future mobile learning could be a huge factor in getting unsatisfied people in learning, where more traditional methods have failed. As mobile phones combine PDA functions with cameras, video and MP3 players, and as tablets combine the portability of PDAs with the functionality of desktops, the world of learning becomes more mobile, more flexible and more exciting. 


\section{HyBRID MOBILE APPLICATION TECHNOLOGY}

Hybrid is derived from heterogeneous sources, or composed of elements of different or unsuitable kinds. A hybrid application is one that is written with the same technology used for websites and mobile web implementations, and that is hosted or runs inside a native container on a mobile device. It is the integration of web technology and native execution. PhoneGap is an example of the most popular container for creating hybrid mobile application[3] [4].

Hybrid application use a web view control (UIWebView on iOS, WebView on Android and others) to present the HTML and JavaScript files in a full-screen format, using the native browser rendering engine. WebKit is the browser rendering engine that is used on iOS, Android, Blackberry and others. That means that the HTML and JavaScript used to construct a hybrid application is rendered/processed by the WebKit rendering engine (for you Windows 8 folks, this is what the IE10 engine does for Metro style applications that use WinJS) and displayed to the user in a full-screen web view control, not in a browser. No longer are you constrained to using HTML and JavaScript for only in-browser implementations on mobile devices.

Mobile SDK supports building three types of applications :

- Native applications are built for a specific platform with the platform SDK, tools and languages, typically provided by the platform vendor (e.g. xCode /Objective-C for iOS, Java for Android, Visual Studio/C\# for Windows Phone).

- Mobile Web applications are server-side applications, built with any server-side technology (PHP, Node.js, ASP.NET) that render HTML that has been styled so that it renders well on a device form factor.

- Hybrid applications, like native applications, run on the device, and are written with web technologies (HTML5, CSS and JavaScript). Hybrid applications run inside a native container, and leverage the device's browser engine to render the HTML and process the JavaScript locally. A web-to-native abstraction layer enables access to device capabilities that are not accessible in Mobile Web applications, such as the camera and local storage.

A graph that highlights the differences in native, hybrid and mobile web applications can be seen in Figure 1.

The hybrid applications is the implementation of an abstraction layer that exposes the device capabilities (native APIs) to the hybrid application as a JavaScript API. This is not possible with Mobile Web implementations because of the security boundary between the browser and the device APIs. PhoneGap is an example of a JavaScript abstraction layer over native APIs. Through this abstraction layer a common set of APIs is exposed in JavaScript, and these JavaScript APIs work on any device supported by the framework.

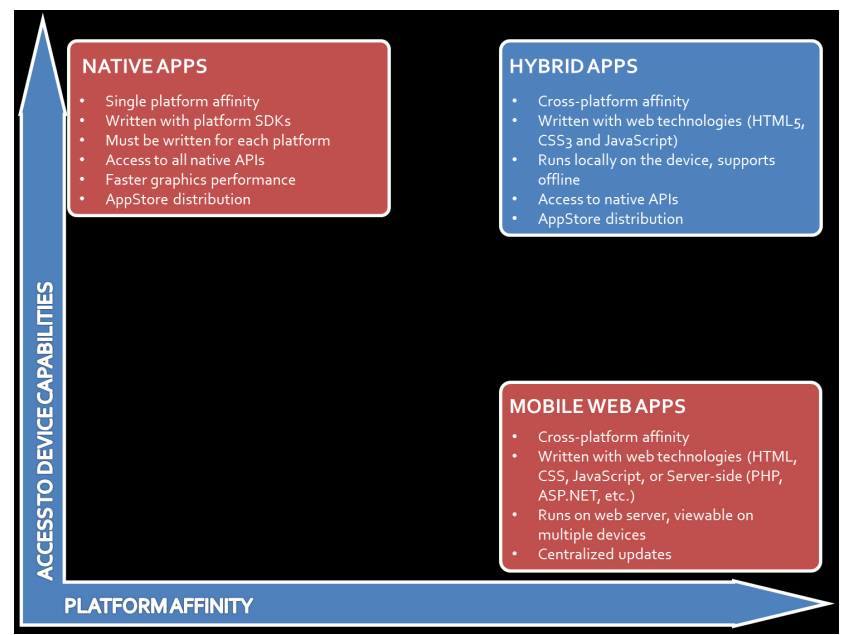

Fig. 1. Three Types of Applications [4]

\section{PHONEGAP}

PhoneGap is an open source framework to create native mobile applications using HTML, CSS, and JavaScript [1]. PhoneGap can be used for iPhone, Android, BlackBerry, Palm webOS, and Symbian WRT (Nokia). To use PhoneGap, a developer also needs to learn how to use the device Standard Development Kit and its tools. The advantage of using PhoneGap is a mobile web developer can put the application and make it a native application that can be installed (or purchased) by the end user.

As a native application, PhoneGap can access certain capabilities that are not found in web applications, such as access to contacts, geolocation, camera, and accelerometer. The ability to use the PhoneGap JavaScript APIs from PhoneGap. To create a native application using PhoneGap, developers get started with writing a mobile web application using HTML, CSS, and JavaScript. According Firtman (2012), PhoneGap is not a browser, but a framework that can create hybrid applications. PhoneGap is a framework that uses native browser engine. In other words, PhoneGap is a native application with a web application in it.

\section{REQUIREMENT ANALYSIS}

To get the user requirements, this research managed as many as 80 respondents students of Petra Christian University from Informatics Department. A total of 3 student respondents do not have a smartphone and 77 other student respondents have a smartphone. Of the 77 respondents, the Blackberry operating system is the most widely used on smartphones student respondents. Table I shows the variation of student respondents smartphone operating system.

Based on the results of the questionnaire, the reason to open the e-learning is to download the course material. This is the most widely chosen feature of the respondents, there are as many as 80 respondents. Table II shows the reasons to open the e-learning. 
TABLE I. VARIOUS SMARTPHONE OPERATING SYSTEMS BEING USED BY STUDENTS

\begin{tabular}{|c|c|c|c|}
\hline \multicolumn{2}{|c|}{ Operating Systems } & \multirow{2}{*}{ Quantity } & \multirow{2}{*}{ Total } \\
\hline Name & Version & & \\
\hline \multirow{4}{*}{ Blackberry } & $(n / a)$ & 11 & \multirow{4}{*}{48} \\
\hline & 5 & 13 & \\
\hline & 6 & 19 & \\
\hline & 7 & 5 & \\
\hline \multirow{5}{*}{ Android } & $(n / a)$ & 3 & \multirow{5}{*}{19} \\
\hline & 2.2 & 3 & \\
\hline & 2.3 & 11 & \\
\hline & 2.4 & 1 & \\
\hline & 3.2 & 1 & \\
\hline \multirow{2}{*}{$\mathrm{iOS}$} & 4 & 2 & \multirow{2}{*}{7} \\
\hline & 5 & 5 & \\
\hline Others & - & 3 & 3 \\
\hline
\end{tabular}

TABLE II. THE REASONS TO OPEN THE E-LEARNING

\begin{tabular}{|c|c|}
\hline Reason & Total \\
\hline Download of course material & 80 \\
\hline Upload of assignment & 64 \\
\hline News & 32 \\
\hline View the Grade & 32 \\
\hline Forum & 25 \\
\hline Message & 11 \\
\hline Chatting & 4 \\
\hline Kalendar & 18 \\
\hline Others & 1 \\
\hline
\end{tabular}

Among additional features desired by the respondents, file sharing or storage is the most preferred, as many as 43 respondents. Table III shows the additional features selected by the respondents.

TABLE III. AdDitional FEATURES SELECTED By RESPONDENTS

\begin{tabular}{|c|c|}
\hline Features & Total \\
\hline File sharing/storage & 43 \\
\hline Notification & 40 \\
\hline Schedule & 30 \\
\hline Posting ke Facebook & 26 \\
\hline Group discussion & 20 \\
\hline Calendar & 13 \\
\hline Contact & 9 \\
\hline Camera & 6 \\
\hline Geo location & 6 \\
\hline Accelerator & 5 \\
\hline Favourite link & 4 \\
\hline Kompas & 2 \\
\hline Game & 1 \\
\hline
\end{tabular}

From the results of questionnaires and interviews, can be found the needs of the new system. Summary of the requirements are:

a. Operating system for Android applications is version 2.3 and the Blackberry version 6. It is based on the number of the most widely used smartphone respondents. In addition to the BlackBerry version 6 there are more features that can support the implementation of the new system compared to the BlackBerry version 5.

b. Users with the role as "student" does not need to register themselves (Enrol) on a course. In addition, users with the role as "teacher" does not need to add a course. This is due to the synchronization process is executed by the system everyday.

c. Users with the role as "teacher" can manage the course is taught, such as changing the course settings and manage the sections contained in the weekly course outline.

As a summary, the features contained in this application are:

a. Assignment tasks by the user with the role as "teacher" and a submitting assigments by the user with the role as "student".

b. Chat which facilitates to make the conversations between users.

c. The discussion forum facilitates to discuss matters relating to a subject.

d. Message which facilitates to send private messages to other users.

e. Resource which facilitates to explore the lecture material.

\section{CONCEPTUAL DESIGN}

The mobile learning application are not acessed using a web browser, but by running the application that have been installed on the smartphone. Firstly, the application running on smartphones make a data request to the server. Then the data sent from the server to the application on the smartphone. Comparison between the web based with the mobile application can be seen in Table IV.

TABLE IV. COMPARISON OF WeB BASED AND MobILE APPLICATION

\begin{tabular}{|c|c|}
\hline Web based & Mobile Application \\
\hline $\begin{array}{c}\text { Administrator can change } \\
\text { the theme on the website }\end{array}$ & $\begin{array}{c}\text { Interface modified as } \\
\text { needed and can not be } \\
\text { customized }\end{array}$ \\
\hline $\begin{array}{c}\text { Users can upload files } \\
\text { stored on the computer }\end{array}$ & $\begin{array}{c}\text { Users can upload files in the } \\
\text { root folder only on the } \\
\text { smartphone }\end{array}$ \\
\hline $\begin{array}{c}\text { The files are uploaded to the } \\
\text { server can be stored on the } \\
\text { folder chosen by the user }\end{array}$ & $\begin{array}{c}\text { The files are uploaded to the } \\
\text { server can only be stored in } \\
\text { the root folder }\end{array}$ \\
\hline $\begin{array}{c}\text { Users can only see the } \\
\text { personal message that has } \\
\text { not been read }\end{array}$ & $\begin{array}{c}\text { Users can see all the private } \\
\text { messages received }\end{array}$ \\
\hline
\end{tabular}




\section{EXPERIMENTAL RESULT}

This implementation is done at the server and smartphone. Implementation on the server using the PHP programming language, while the implementation of the smartphone using PhoneGap [1] and jQuery Mobile framework programming language [2] that uses HTML 5 [7], CSS 3 and JavaScript [6]. Tests performed on the BlackBerry Curve 3G smartphone running BlackBerry OS version 6 and Samsung Galaxy Pocket that uses the Android operating system version 2.3.6. Testing was conducted on the test menu application, case studies, and questionnaires.

Implementation of programs on smartphones is done by running the installer file. Application can be used after the installation is complete. On smartphones with Android operating system, the user can select a file with the installer file format. Apk, whereas the BlackBerry smartphone using the file format. Cod and. Jad.

Course used for testing is "Library Information System 2/2011". This course is a course in Informatics Department which held in the second semester of academic year 2011/2012. This course consists of a general section 1 until section 18 weekly and is taught by one lecturer.

Testing is done by adding a section to the 19th section. After that, the section is filled with modules such as forums, assignments, and so on. Figure 2 shows a form of edit course on the BlackBerry is used to add a the $19^{\text {th }}$ section. Figure 3 shows a form edit course on Android. Figure 4 shows the display of section $19^{\text {th }}$ on BlackBerry just added, while Figure 5 shows the display section $19^{\text {th }}$ on Android.

\begin{tabular}{l} 
Summary \\
Sistem Informasi Perpustakaan - 2nd \\
Semester 2011/2012 \\
\hline Number of weeks/topics \\
\hline 19 Course start date
\end{tabular}

Fig. 2. Form Edit Course on BlackBerry

\begin{tabular}{l} 
Lil \\
Summary \\
$\begin{array}{l}\text { Sistem Informasi Perpustakaan - 2nd } \\
\text { Semester 2011/2012 }\end{array}$ \\
Number of weeks/topics \\
19 \\
Course start date \\
16 \\
(Day) \\
2 \\
(Month) \\
2012 \\
\hline
\end{tabular}

Fig. 3. Form Edit Course on Android

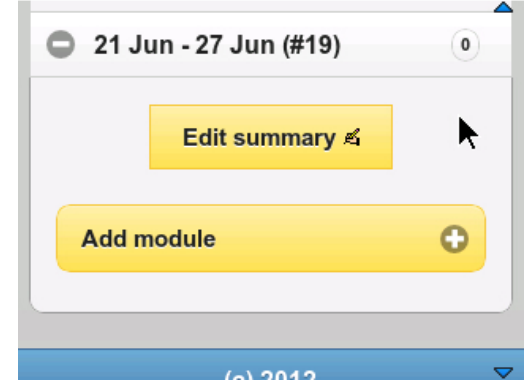

Fig. 4. Display Section 19 on BlackBerry

Display section $19^{\text {th }}$ after adding the modules can be seen in Figure 6 for BlackBerry, and Figure 7 for Android. Figure 8 shows the view of section $19^{\text {th }}$ on the Lentera website as a comparison.

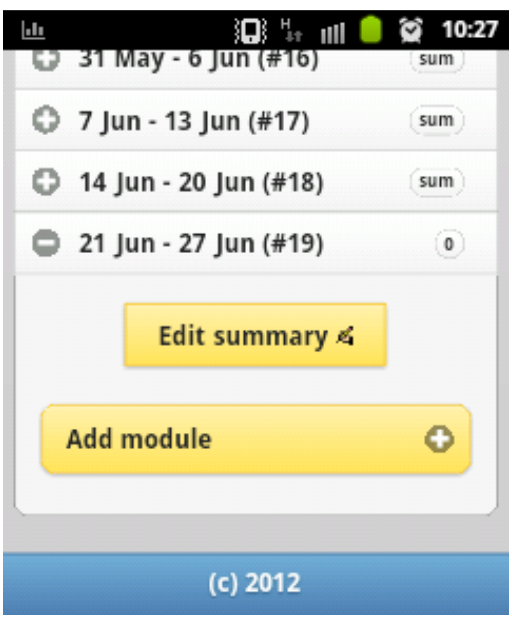

Fig. 5. Display Section 19 on Android

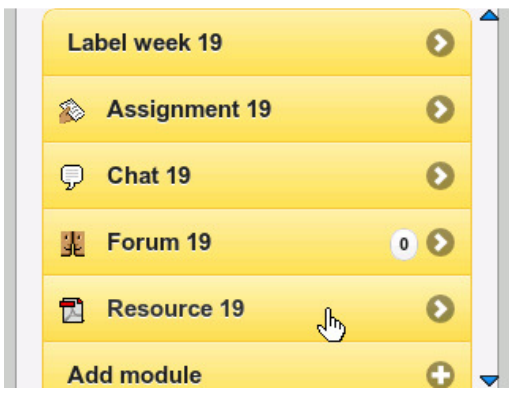

Fig. 6. New Display Section 19 on BlackBerry 


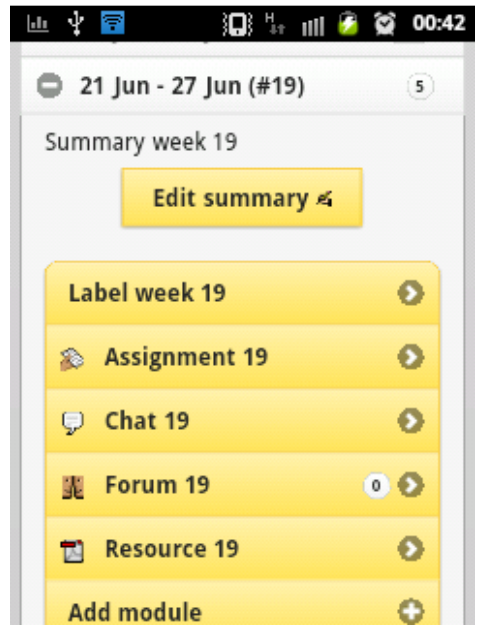

Fig. 7. New Display Section 19 on Android

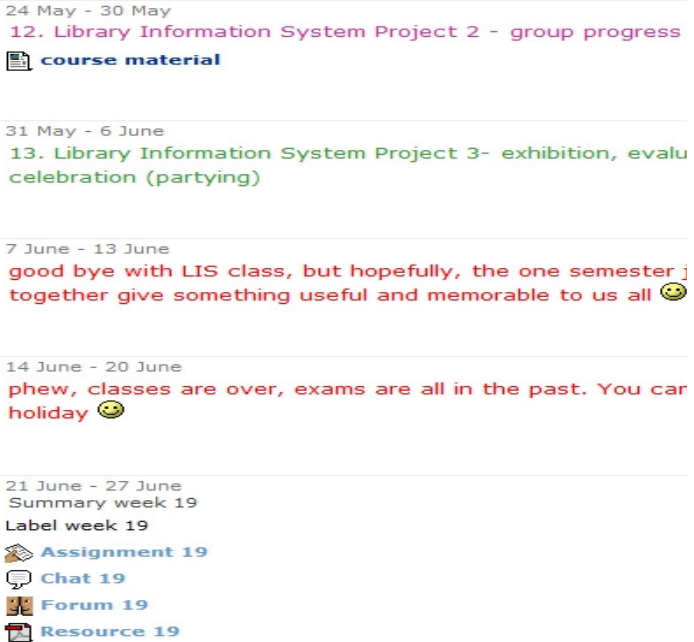

Fig. 8. New Display Section 19 on Web Based Browser

\section{CONCLUSION}

- Applications can run on cross platforms (Android dan Blackberry) using the same source code.

- Basic features contained in web version "Lentera" has been successfully implemented on this application. Such features include file download course material, assignments, chat, forums, notification, send messages and file upload feature.

- The features in the application can be used in the learning process. It is known from the results of questionnaires, as many as $66.67 \%$ of respondents answered very helpful and $33.33 \%$ of respondents answer helpful.

- The process to produce a file that can be installed on a platform having different levels of ease. Registration required on the BlackBerry platform and the installation of on application signing keys, while on Android platform does not require it.

- Not all code HTML, CSS and JavaScript are supported by a platform. In addition, the platform also has a new code that can be used to support such platforms like on BlackBerry platform

\section{REFERENCES}

[1] Allen, S., Groupera, V. \& Lundrigan, L. Pro smartphone cross-platform development: iPhone, blackberry, windows mobile and android development and distribution. United States of America: Apress, 2010

[2] Firtman, M. jQuery mobile: up and running. United States of America: O'Reilly, 2012.

[3] Korf M. and Oksma E. Native, HTML5, or Hybrid: Understanding Your Mobile Application Development Options. Retrieved April 10 2013. http://wiki.developerforce.com

[4] Seven D., What is a Hybrid Mobile App?, Retrieved April 10, 2013. http://www.icenium.com/

[5] The Excellence Gateway. What is Mobile Learning? Retrieved April 2, 2013. http://archive.excellencegateway.org.uk

[6] W3Schools. (n.d.). CSS3 introduction. Retrieved April, 20, 2012 http://www.w3schools.com/html/css3_intro.asp

[7] W3Schools. (n.d.). HTML5 introduction. Retrieved January, 16, 2013. http://www.w3schools.com/html/html5_intro.asp 